\title{
EPR studies of recombinant horse L-chain apoferritin and its mutant (E 53,56,57,60 Q) with haemin
}

\author{
Natalia deVal ${ }^{1}$, Wilfred R. Hagen ${ }^{2} \&$ Robert R. Crichton ${ }^{1, *}$ \\ ${ }^{1}$ Unit of Biochemistry, Department of Chemistry, Université Catholique de Louvain, Bâtiment Lavoisier, \\ 1 Place Louis Pasteur, 1348, Louvain-la-Neuve, Belgium; ${ }^{2}$ Department of Biotechnology, Delft University of \\ Technology, Julianalaan 67, Delft, 2628 BC, The Netherlands; *Author for correspondence \\ (E-mail: crichton@bioc.ucl.ac.be)
}

Received 9 November 2005; accepted 27 March 2006

Key words: ferritin, bacterioferritin, EPR, haemin, demetallation

\begin{abstract}
Structural similarities between ferritins and bacterioferritins have been extensively demonstrated. However, there is an essential difference between these two types of ferritins: whereas bacterioferritins bind haem, in-vivo, as Fe(II)-protoporphyrin IX (this haem is located in a hydrophobic pocket along the 2-fold symmetry axes and is liganded by two axial Met 52 residues), eukaryotic ferritins are non-haem iron proteins. However, in in-vivo studies, a cofactor has been isolated from horse spleen apoferritin similar to protoporphyrin IX; in in-vitro experiments, it has been shown that horse spleen apoferritin is able to interact with haemin (Fe(III)-protoporphyrin IX). Studies of haemin incorporation into horse spleen apoferritin have been carried out, which show that the metal free porphyrin is found in a pocket similar to that which binds haem in bacterioferritins (Précigoux et al. 1994 Acta Cryst D50, 739-743). A mechanism of demetallation of haemin by L-chain apoferritins was subsequently proposed (Crichton et al. 1997 Biochem 36, 1504915054) which involved four Glu residues (E 53,56,57,60) situated at the entrance of the hydrophobic pocket and appeared to be favoured by acidic conditions. To verify this mechanism, these four Glu have been mutated to Gln in recombinant horse L-chain apoferritin. We report here the EPR spectra of recombinant horse L-chain apoferritin and its mutant with haemin in basic and acidic conditions. These studies confirm the ability of recombinant L-chain apoferritin and its mutant to incorporate and demetallate the haemin in acidic and basic conditions.
\end{abstract}

\section{Introduction}

The importance of the iron in biology reflects both its chemical versatility and its abundance. The second most abundant metal in the earth's crust, it is a member of the transition elements, so designated because they have incompletely filled $\mathrm{d}$ orbitals. As a consequence, one of the important properties of iron is its ability to change valence. It has the possibility of various oxidation states (from -II to + IV), the principal ones being ferrous, $\mathrm{Fe}(\mathrm{II})$ and ferric, $\mathrm{Fe}(\mathrm{III})$. Whereas $\mathrm{Fe}(\mathrm{II})$ is extremely water soluble, $\mathrm{Fe}(\mathrm{III})$ is quite insoluble in water although significant concentrations of water-soluble $\mathrm{Fe}^{3+}$ species can be attained by complex formation. $\mathrm{Fe}(\mathrm{II})$ and $\mathrm{Fe}(\mathrm{III})$ have a maximum co-ordination number of 6 , although four- or particularly five-co-ordinate complexes are also encountered. The stereochemistry of both $\mathrm{Fe}(\mathrm{II})$ and $\mathrm{Fe}(\mathrm{III})$ is tetrahedral for four-co-ordinate and trigonal bipyramidal or square pyramidal for five-co-ordinate and octahedral for six-coordinated complexes such as $\mathrm{Fe}\left(\mathrm{H}_{2} \mathrm{O}\right)_{6}{ }^{2+}$ (Crichton 2001).

Most of the iron present in living organisms is complexed in proteins, although it may also be 
present in a soluble pool of low molecular weight complexes (Weaver \& Pollack 1989). Uncomplexed iron together with superoxide (which reduces Fe(III), (1) and hydrogen peroxide (which is decomposed by the Fenton reaction, (2) (Fenton 1984) provide a lethal mixture generating reactive hydroxyl radicals. The sum of these reactions is the Haber-Weiss reaction (3) (Haber \& Weiss 1934).

$$
\begin{aligned}
& \mathrm{Fe}^{3+}+\mathrm{O}^{2-} \rightarrow \mathrm{Fe}^{2+}+\mathrm{O}_{2} \\
& \mathrm{Fe}^{2+}+\mathrm{H}_{2} \mathrm{O}_{2} \rightarrow \mathrm{Fe}^{3+}+\mathrm{OH}^{-}+\mathrm{OH}^{\cdot} \\
& \mathrm{O}^{2-\cdot}+\mathrm{H}_{2} \mathrm{O}_{2} \rightarrow \mathrm{OH}^{-}+\mathrm{OH}^{-}+\mathrm{O}_{2}
\end{aligned}
$$

The hydroxyl radical is very reactive causing lipid peroxidation, DNA damage and degradation of other biomolecules (Halliwell \& Guttheridge 1984).

Sequestration of iron in a soluble, bioavailable and non-toxic form is achieved by iron storage proteins, the ferritins and bacterioferritins, which are widely distributed throughout in living organisms.

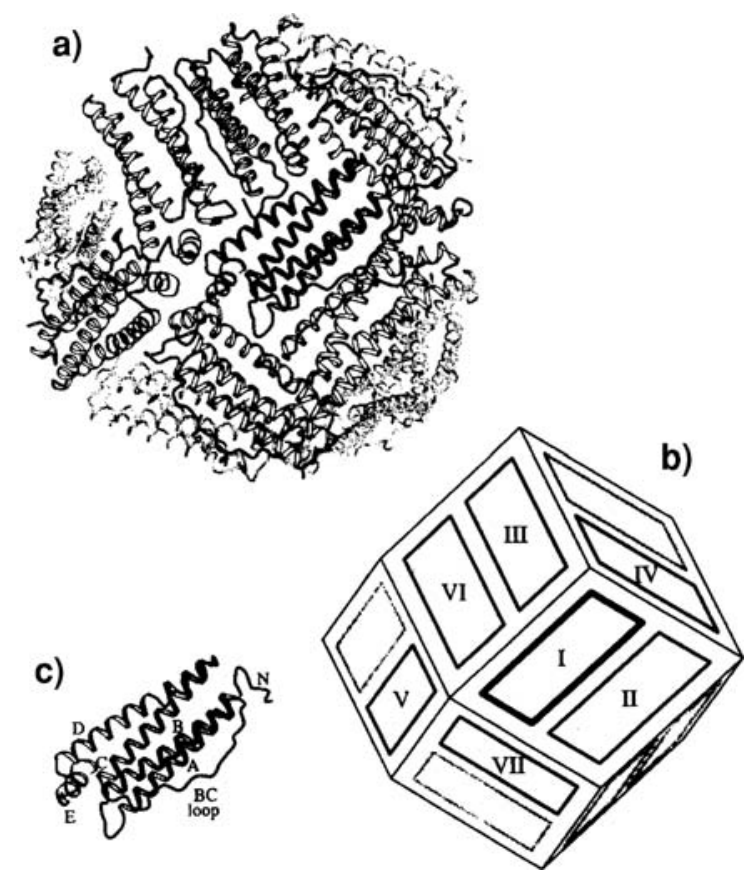

Figure 1. (a) Overview of a ferritin molecule showing the relative positions and interfaces between symmetry related subunits. (b) Labelling scheme of symmetry related subunits. (c) Detail of a single ferritin subunit (Hempstead et al. 1997).
Ferritin are oligomeric proteins of 24 identical or similar subunits related by 432 symmetry (Figure 1), each of molecular weight around $20 \mathrm{kDa}$, forming a hollow protein shell of $120 \AA$ external diameter and $80 \AA$ internal diameter (Ford et al. 1984). The molecular weight ranges from 450 to $500 \mathrm{kDa}$, and up to 4500 iron atoms can be stored in its internal cavity in mammalian ferritins in the form of ferrihydrite micelles.

Each subunit is a bundle of four long $\alpha$-helices composed of two pairs of antiparallel helices A, B, C and $\mathrm{D}$ with a fifth shorter helix $\mathrm{E}$, a short non helical extension at the $\mathrm{N}$ - and $\mathrm{C}$-termini and a long loop (L) between the B and C helices. B and D helices are located on the interior of the protein shell whereas the $\mathrm{A}$ and $\mathrm{C}$ helices and the $\mathrm{L}$ loop are on the external surface of the molecule (Ford et al. 1984).

Bacterial ferritins are generally composed of a single subunit type, however the majority of mammalian ferritins are composed of two types of subunits: H-chains and L-chains (Harrison et al. 1991; Andrews et al. 1992). Following the Drysdale model, the two types of subunits can form 25 different heteropolymers (Drysdale 1977). Hchains catalyse the oxidation of $\mathrm{Fe}$ (II) to $\mathrm{Fe}$ (III) (ferroxidase activity) and the functional importance of L-chains is thought to reside primarily in their ability to promote nucleation of the ferrihydrite core; it has been demonstrated that these two chains have co-operative roles in iron mobilisation (Bauminger et al. 1991; Levi et al. 1992; Bauminger et al. 1994; Santambrogio et al. 1996).

Apoferritin presents intersubunit channels which communicate between the inside of the molecule and the external environment: eight hydrophilic channels along the 3-fold and six hydrophobic channels along the 4-fold symmetry axes (Harrison \& Arosio 1996). The possible pathways by which iron might penetrate into the protein include these channels. The X-ray crystallographic observation of metal binding sites suggests that the 3 -fold channels are the most likely route of iron entry into animals ferritins (Lawson et al. 1991; Hempstead et al. 1997; Granier et al. 1998).

This paper reports an EPR study of the demetallation of haemin by recombinant horse L-chain apoferritin and its mutant (E 53,56,57,60 Q) in acidic and basic conditions. The four glutamates situated at the entrance of the hydrophobic pocket, have been implicated in this process (Crichton et al. 1997). 
EPR spectroscopy is used here to monitor the time conversion of an iron (III) haem signal into an iron (III) non-haem signal under different reaction conditions.

\section{Materials and methods}

\section{Materials}

The materials used to prepare the recombinant L-chain apoferritin and its mutant (E 53,56,57,60 Q) for the incorporation of haemin are: Bovine haemin chloride (Sigma Aldrich, St. Louis, USA), $\mathrm{NaN}_{3}$ (Merck, Darmstadt, Germany), Casein hydrolysate (Merck, Darmstadt, Germany), Yeast extract (Merck, Darmstadt, Germany), $\mathrm{NaCl}$ (Fisher Scientific, London, UK), Ammonium sulphate (Acros Organics, New Jersey, USA), TRIS ultrapure (Applichem Biochemica, Darmstadt, Germany), Sephacryl S-300 (Pharmacia, Uppsala, Sweden), Thioglycolic acid (Acros Organics, New Jersey, USA), $\mathrm{NaOH}$ (Merck, Darmstadt, Germany), Ammonium bicarbonate (Merck, Darmstadt, Germany), Sodium acetate (Merck, Darmstadt, Germany), Sodium cacodylate (Fluka, Biochemica, Darmstadt, Germany), $\mathrm{Na}_{2} \mathrm{HPO}_{4}$ (Merck, Darmstadt, Germany), Bradford reagent (Biorad, München, Germany), Dialysis membranes (Medicell International, Ltd, London, UK) and microconcentrators (Vivapore $5 \mathrm{ml}$, Vivascience, Sartorius group).

\section{Methods}

Expression of recombinant horse L-chain ferritin and its mutant (E 53,56,57,60 Q)

The E. coli strain BMH-71-18 was transformed with the plasmid pMK2100 which is the fusion of the cDNA coding for horse L-chain ferritin and a vector pTZ18U. This expression vector controls the expression of the ferritin gene with a promoter tac which is present together with the $A m p^{r}$ gene in the same plasmid (Takeda et al. 1993).

A bacterial colony containing the appropriate plasmid or $30 \mu \mathrm{l}$ of the bacterial solution conserved in glycerol at $-80{ }^{\circ} \mathrm{C}$ was incubated in $70 \mathrm{ml}$ of $2 \mathrm{xTY}$-Amp medium and left shaking at $37{ }^{\circ} \mathrm{C}$ overnight. Afterwards, $50 \mathrm{ml}$ of the resulting culture was incubated in $250 \mathrm{ml}$ of fresh medium at $37{ }^{\circ} \mathrm{C}$, with shaking for $24 \mathrm{~h}$. At the end of the growth phase, the culture was kept in an ice bath for $10 \mathrm{~min}$, centrifuged at $10000 \mathrm{rpm}$ for $25 \mathrm{~min}$, resuspended in a solution of $\mathrm{NaN}_{3} 0.02 \%$ $(\mathrm{w} / \mathrm{v})$ and stored at $-20{ }^{\circ} \mathrm{C}$.

Purification of recombinant horse L-chain ferritin and its mutant (E 53,56,57,60 Q)

The bacterial cells were lysed by sonication on ice. The supernatant, after centrifugation at $10000 \mathrm{rpm}$ for $30 \mathrm{~min}$, was subjected to a thermal denaturation step at $65{ }^{\circ} \mathrm{C}$ for $10 \mathrm{~min}$ in a shaking water bath. After centrifugation at $15000 \mathrm{rpm}$ for $20 \mathrm{~min}$, the supernatant underwent ammonium sulphate precipitation $(56 \% \mathrm{w} / \mathrm{v})$ at $4{ }^{\circ} \mathrm{C}$, and the pellet, after centrifugation at $15000 \mathrm{rpm}$ for 15 min was resuspended in a minimal volume of $25 \mathrm{mM}$ Tris- $\mathrm{HCl}$ buffer, $\mathrm{pH} 7,5$ and dialysed against the same buffer during $24 \mathrm{~h}$. Thereafter, the final step in the purification involved chromatography on Sephacryl S-300.

\section{Apoferritin preparation}

Apoferritin was prepared from recombinant L-chain ferritin by dialysing against $0.5 \%(\mathrm{v} / \mathrm{v})$ thioglycolic acid, $\mathrm{pH}$ adjusted to 5.5 with $\mathrm{NaOH}$ $6 \mathrm{M}$, for $24 \mathrm{~h}$ at room temperature (Bryce \& Crichton 1973). The excess of thioglycolic acid was removed by dialysing against ammonium bicarbonate $0.5 \%(\mathrm{w} / \mathrm{v})$ for $24-48 \mathrm{~h}$. After this time, the apoferritin was dialysed against the appropriate buffer before use. In our case, the three buffers

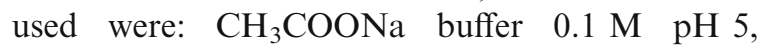
$\mathrm{C}_{2} \mathrm{H}_{6} \mathrm{AsNaO}_{2} \times 3 \mathrm{H}_{2} \mathrm{O}$ buffer $0.1 \mathrm{M}$ pH 8 and $\mathrm{Na}_{2} \mathrm{HPO}_{4}$ buffer $0.1 \mathrm{M} \mathrm{pH} 8$.

\section{Concentration of recombinant horse L-chain} apoferritin and its mutant (E 53,56,57,60 Q) and incubation with haemin

After determination of the protein concentration by the Bradford reagent (Bradford et al. 1976), the protein was concentrated from 0.5 to $10-20 \mathrm{mg} / \mathrm{ml}$ with the Vivapore method $5 \mathrm{ml}$ concentrator (Vivascience, Sartorius Group). After the concentration, the protein was incubated with eight molecules of haemin per molecule of apoferritin (haemin was dissolved in $\mathrm{NH}_{4} \mathrm{HCO}_{3} 0.1 \mathrm{M}$ buffer to have a stock concentration of $8 \mathrm{mM}$ ).

\section{EPR spectroscopy}

EPR spectra were taken on a Bruker 200 D spectrometer equiped with a helium flow cooling system and with data acquisition facilities as de- 
scribed in (Pierik \& Hagen 1991). All data were taken under the following conditions: microwave frequency, $9.44 \mathrm{GHz}$; microwave power, $8 \mathrm{~mW}$; modulation frequency, $100 \mathrm{kHz}$; modulation amplitude, 6.3 Gauss; temperature $16 \mathrm{~K}$. These conditions are a compromise between optimal conditions for the detection of the haemin signal and optimal conditions for the non-haemin signal. The spectra were simulated as effective $S=1 / 2$ systems subject to $g$-strain as in (Hagen et al. 1985). The non-haemin signal $(g \approx 4.3)$ is from the middle Kramers doublet of a rhombic $S=5 / 2$ system and the haemin signal $(g \approx 6$ and 2$)$ is from the lowest Kramers doublet of a near-axial $S=5 / 2$ signal (cf. Hagen 1992). In order to relate an amplitude ratio of the two signals, $A_{g=4.3} / A_{g=6}$, to a concentration ratio, [non-haemin $\mathrm{Fe}(\mathrm{III})] /[$ haemin $\mathrm{Fe}(\mathrm{III})]$, we assumed a small zero-field splitting, $D<2 \mathrm{~cm}^{-1}$, for the non-haemin iron (Dowsing \& Gibson 1969), which implies 33\% population of the observed doublet, and a $D=10 \mathrm{~cm}^{-1}$ for the haemin signal (Van Kan et al. 1998), which implies $84 \%$ of the observed doublet.

\section{Results and discussion}

L-chain recombinant ferritin ("wild type") and mutant E 53,56,57,60Q ("mutant") at relatively low concentrations of around $10 \mathrm{mg} / \mathrm{ml}$, or $21 \mu \mathrm{M}$ 24-mer, were incubated with eight hemin per 24mer for prolonged time periods under different buffering conditions.

A few representative EPR spectra and simulations are given for the high-spin Fe(III) haemin bound to ferritin and for the high-spin non-haemin $\mathrm{Fe}(\mathrm{III})$ assumed to result from demetallation (Figure 2). The shape of both the haemin and the non-haemin $\mathrm{Fe}(\mathrm{III})$ signals were identical for the wild type and for the mutant in which the four glutamates had been changed to glutamines. Also, the spectral shapes were independent of the $\mathrm{pH}$ (5 versus 8) and independent of the buffer used. This implies that in order to compare the time course of haemin demetallation in wild type versus mutant and under different buffering conditions, it is sufficient to compare the ratios of the amplitudes of the EPR at $g=4.3$ (non-haemin iron) over $g=6$ (haemin iron). Using the procedure described in the Methods section it was determined that an amplitude ratio of approximately 2 corresponds to

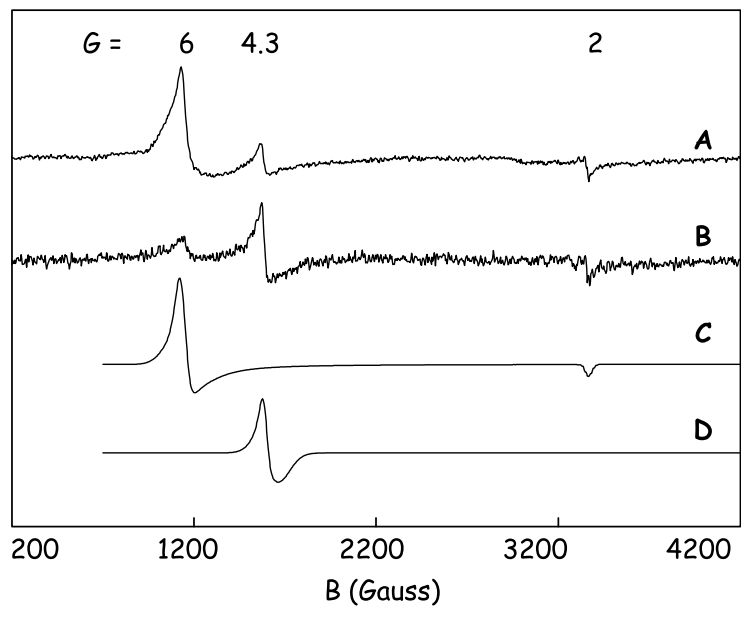

Figure 2. EPR spectra of recombinant horse L-chain ferritin. The two upper traces are experimental spectra from $20-35 \mu \mathrm{M}$ E 53,56,57,60Q mutant after 3 months incubation with eight hemin per 24-mer in sodium phosphate buffer, $\mathrm{pH} 8$ (trace A) or in sodium acetate buffer, $\mathrm{pH} 5$ (trace $\mathrm{B}$ ). The lower two traces are simulations of the haemin $\mathrm{Fe}$ (III) signal with $g=5.9$, 5.9, 2 (trace C) or the non- haemin Fe(III) signal with $g=4.1$, $4.25,4.4$ (trace D). See the Methods section for experimental conditions and simulation protocol.

equal concentrations of haemin iron and nonhaemin iron. In other words, detection of an amplitude ratio of 2 implies that demetallation of the haemin has proceeded to an extent of $50 \%$. Use of the amplitude ratio has the added advantage that it is insensitive to fluctuations in the experimental set-up, which may occur over the long period between measurements of up to 6 months. The amplitude ratio should also be insensitive to possible loss of signal intensity by small amounts of reduction to $\mathrm{Fe}(\mathrm{II})$ under the assumption that this reduction occurs equally well for the non-haemin as for the haemin iron.

Double integration of EXPERIMENTAL spectra is done in order to correct for spectral shape/width and for intensity (= transition probability). By making computer SIMULATIONS (Hagen et al. 1985) of experimental spectra this double-integration procedure is no longer necessary, because the shape and the transition probability are part of the simulation.

The development of the EPR intensity ratio is given after a period of 15 days, 3 months and 6 months (Table 1). From the data in Table 1 it is concluded that: (i) haemin demetallation in the wild type is more efficient than in the mutant, however, it is far from zero in the mutant; (ii) 
Table 1. EPR intensity ratio between non-haemin iron (III) and haemin iron (III) $(g=4.3 / g=6)$ for recombinant wild type L-chain apoferritin and its mutant (E 53,56,57,60Q) under different reaction conditions.

\begin{tabular}{|c|c|c|c|c|c|c|c|}
\hline \multicolumn{4}{|c|}{$\begin{array}{l}\text { Recombinant mutant (E 53,56,57,60Q) horse L-chain } \\
\text { apoferritin }^{\text {a }}\end{array}$} & \multicolumn{4}{|c|}{ Recombinant wild type horse L-chain apoferritin ${ }^{\mathrm{a}}$} \\
\hline \multirow[t]{2}{*}{$\operatorname{Time}^{\mathrm{b}}$} & \multicolumn{3}{|l|}{ Buffers } & \multirow[t]{2}{*}{ Time } & \multicolumn{3}{|l|}{ Buffers } \\
\hline & $\begin{array}{l}\mathrm{CH}_{3} \mathrm{COONa} \\
0.1 \mathrm{M} \mathrm{pH} 5^{\mathrm{d}}\end{array}$ & $\begin{array}{l}\mathrm{C}_{2} \mathrm{H}_{6} \mathrm{AsNaO}_{2} \times 3 \mathrm{H}_{2} \mathrm{O} \\
0.1 \mathrm{M} \mathrm{pH} 8^{\mathrm{e}}\end{array}$ & $\begin{array}{l}\mathrm{Na}_{2} \mathrm{HPO}_{4} \\
0.1 \mathrm{M} \mathrm{pH} 8^{\mathrm{f}}\end{array}$ & & $\begin{array}{l}\mathrm{CH}_{3} \mathrm{COONa} \\
0.1 \mathrm{M} \mathrm{pH} 5^{\mathrm{g}}\end{array}$ & $\begin{array}{l}\mathrm{C}_{2} \mathrm{H}_{6} \mathrm{AsNaO}_{2} \times 3 \mathrm{H}_{2} \mathrm{O} \\
0.1 \mathrm{M} \mathrm{pH} 8^{\mathrm{h}}\end{array}$ & $\begin{array}{l}\mathrm{Na}_{2} \mathrm{HPO}_{4} \\
0.1 \mathrm{M} \mathrm{pH} 8^{\mathrm{i}}\end{array}$ \\
\hline 15 days & 1.17 & 0.40 & 0.14 & 15 days & 1.00 & 0.66 & 0.56 \\
\hline 3 months ${ }^{\mathrm{c}}$ & 4.00 & 0.50 & 0.32 & 3 months & 4.90 & 1.30 & 0.75 \\
\hline 6 months $^{\mathrm{c}}$ & 4.75 & 0.52 & 0.51 & 6 months & 5.25 & 1.43 & 0.80 \\
\hline
\end{tabular}

${ }^{\mathrm{a}}$ These proteins were incubated with eight molecules of haemin per molecule of apoferritine.

${ }^{\mathrm{b}}$ Time of incubation with haemin; the samples were kept at stable temperature $\left(18^{\circ} \mathrm{C}\right)$.

${ }^{\mathrm{c}}$ Ferritin is a very stable protein; longer time of incubation is not a problem for the stability of ferritin; in our experiments, we did not observe the formation of artefact (data not showed).

${ }^{\mathrm{d}}$ Recombinant mutant (E 53,56,57,60Q) horse L-chain apoferritin concentration: $9.94 \mathrm{mg} / \mathrm{ml}$.

${ }^{\mathrm{e}}$ Recombinant mutant (E 53,56,57,60Q) horse L-chain apoferritin concentration: $20.1 \mathrm{mg} / \mathrm{ml}$.

${ }^{\mathrm{f}}$ Recombinant mutant (E 53,56,57,60Q) horse L-chain apoferritin concentration: $17.5 \mathrm{mg} / \mathrm{ml}$.

${ }^{\mathrm{g}}$ Recombinant wild type horse L-chain apoferritin concentration: $8.44 \mathrm{mg} / \mathrm{ml}$.

${ }^{\mathrm{h}}$ Recombinant wild type horse L-chain apoferritin concentration: $9.34 \mathrm{mg} / \mathrm{ml}$.

${ }^{\mathrm{I}}$ Recombinant wild type horse L-chain apoferritin concentration: $15 \mathrm{mg} / \mathrm{ml}$.

demetallation at $\mathrm{pH} 5$ is much more efficient than at $\mathrm{pH} 8$; demetallation is not significantly dependent on the nature of the buffer (cf. phosphate versus cacodylate).

\section{Conclusions}

The recombinant wild type horse L-chain apoferritin and its mutant (E 53,56,57,60 Q) have the ability to incorporate and to demetallate haemin in acidic and basic conditions, but the demetallation is faster at acid $\mathrm{pH}$ than basic $\mathrm{pH}$. This would have important biological consequences, since we know that ferritin is progressively transformed to haemosiderin within the acidic lysosomal compartment.

The first hypothesis to explain the demetallation implicated the four glutamates situated at the entrance of the hydrophobic pocket. From the present study, we conclude that, while these four glutamates are important - demetallation is faster in the wild type than the mutant - nonetheless their mutation does not stop the incorporation and demetallation of haemin. This suggests that another component of the protein, perhaps arginine 59 , which is also located in the hydrophobic pocket (Figure 3), may also be involved.
We are currently constructing two new mutants: R59M and E 53,56,57,60Q/ R59M to verify the importance of arginine 59 in this process.

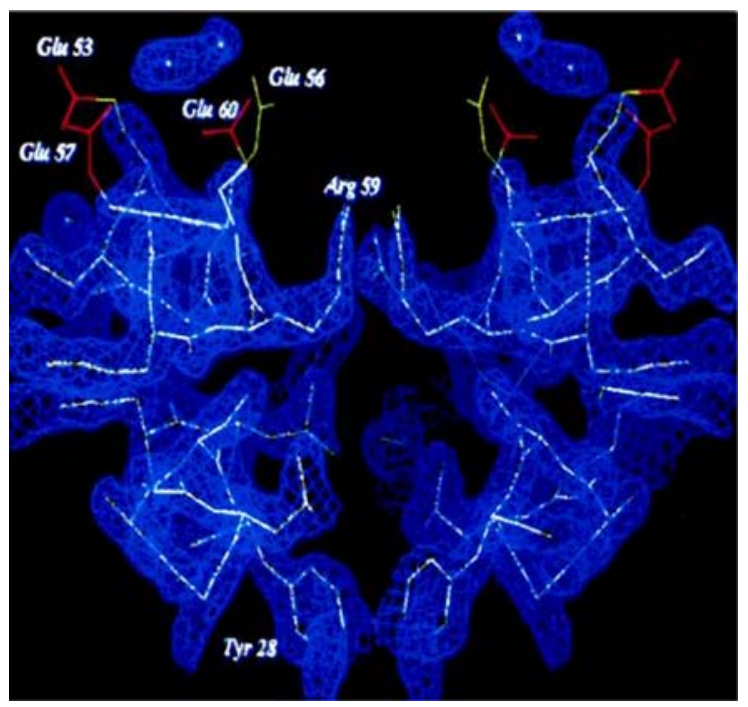

Figure 3. View perpendicular to the 2-fold axis passing through the dimer. The bottom of the porphyrin pocket is lined by the two symmetry related Y28 residues, and the top is represented by the two R59 residues pointing toward the inner cavity of the protein. On each side of the pocket lies the cluster of E 53, E56, E57 and E60. Disordered glutamic side chains are coloured red. Solvent molecules in the close vicinity are shown. $2 F_{\mathrm{o}}-F_{\mathrm{c}}$ electron density maps are contoured at $1.8 \sigma$. (Gallois et al. 1997). 


\section{Acknowledgments}

We thank Professor Dr Louis Hue, Dr Luc Bertrand and Dr Noëlle Carette for producing the ferritin mutant (E 53, 56, 5760 Q). Finally, we thank the Catholic University of Louvain to give us the opportunity to work on this project.

\section{References}

Andrews SC, Arosio P, Bootke W, et al. 1992 Structure, function and evolution of ferritins. J Inorg Biochem 47, 161-174.

Bauminger ER, Harrison PM, Hechel D, Nowik I, Treffry A. 1991 Mossbauer spectroscopy investigation of structurefunction relations in ferritins. Biochim Biophys Acta 1118, 48-58.

Bauminger ER, Treffry A, Hudson JA, et al. 1994 Iron incorporation into ferritins: evidence for the transfer of monomeric $\mathrm{Fe}(\mathrm{III})$ between ferritin molecules and for the formation of an unusual mineral in the ferritin of Escherichia coli. Biochem J 302, 813-820.

Bradford MM, et al. 1976 A rapid and sensitive method for the quantitation of microgram quantities of protein utilizing the principle of protein-dye binding. Anal Biochem 72, 248-254.

Bryce CFA, Crichton RR. 1973 The catalytic activity of horse spleen apoferritin. Preliminary kinetic studies and the effect of chemical modification. Biochem J 133, 301-309.

Crichton RR. 2001 Inorganic Biochemistry of iron metabolism from molecular mechanisms to clinical consequences. Chichester: John Wiley \& Sons, 326.

Crichton RR, Soruco JA, Roland F, et al. 1997 Remarkable ability of horse spleen apoferritin to demetalate hemin and to metalate protoporphyrin IX as a function of $\mathrm{pH}$. Biochem 36(49), 15049-15054.

Dowsing RD, Gibson JF. 1969 Electron spin resonance of highspin d5 systems. J Chem Phys 50, 294-303.

Drysdale JW. 1977 Ciba Fd Symp 51, 41-57.

Fenton HJH. 1984 J Chem Soc Trans 65, 899-910.

Ford GC, Harrison PM, Rice DW, et al. 1984 Ferritin: design and formation of an iron-storage molecule. Phil Trans $R$ Soc Lond B304, 551-565.

Gallois B, Langlois d'Estaintot B, Michaux MA, Dautant A. 1997 J Biol Inorg Chem 2, 360-367.

Granier T, Comberton G, Gallois B, et al. 1998 Evidence of new cadmium binding sites in recombinant horse L-chain ferritin by anomalous Fourier difference map calculation. PROTEINS: Struct. Func. Genet. 31, 477-485.

Haber F, Weiss J. 1934 Proc Roy Soc Ser A 147, 332-333.

Hagen WR. 1992 EPR spectroscopy of iron-sulfur proteins. Adv Inorg Chem 38, 165-222.

Hagen WR, Hearshen DO, Harding LJ, Dunham WR. 1985 Quantitative numerical analysis of $g$ strain in the EPR of distributed systems and its importance for multicenter metalloproteins. J Magn Reson 61, 233-244.

Halliwell B, Guttheridge JMC. 1984 Oxygen toxicity, oxygen radicals, transition metals and disease. Biochem $J$ 219, 1-14.

Harrison PM, Arosio P. 1996 The ferritins: molecular properties, iron storage, function and cellular regulation. Biochim Biophys Acta 1275, 161-203.

Harrison PM, Andrews SC, Artymiuk PJ, et al. 1991 Adv Inorg Chem 36, 449-486.

Hempstead PD, Yewdall SJ, Fernie AR, et al. 1997 Comparison of the three-dimensional structures of recombinant human $\mathrm{H}$ and horse $\mathrm{L}$ ferritins at high resolution. $J$ Mol Biol 268, $424-448$.

Lawson DM, Artymiuk PJ, Yendall SJ, et al. 1991 Solving the structure of human $\mathrm{H}$ ferritins by genetically engineering intermolecular crystal contacts. Nature 349, 541-543.

Levi S, Yendall SJ, Harrison PM, et al. 1992 Evidence of Hand L- chains have co-operative roles in the Iron uptake mechanism of human ferritin. Biochem $J \mathbf{2 8 8}, 591-596$.

Pierik AJ, Hagen WR. $1991 \mathrm{~S}=$ 9/2 EPR signals are evidence against coupling between the siroheme and the $\mathrm{Fe} / \mathrm{S}$ cluster prosthetic groups in Desulfovibrio vulgaris (Hildenborough) dissimilatory sulfite reductase. Eur J Biochem 195, 505-516.

Précigoux G, Yariv J, Gallois B, Dautant A, Courseille C, Langlois d'Estaintot B. 1994 A crystallographic study of haem binding to ferritin. Acta Cryst D50, 739-743.

Santambrogio P, Levi S, Cozzi A, Corsi B, Arosio P. 1996 Evidence that the specificity of iron incorporation into homopolymers of human ferritin L- and $\mathrm{H}$ - chains is conferred by the nucleation and ferroxidase centres. Biochem $J \mathbf{3 1 4}$, 139-144.

Takeda S, Otha M, Ebina S, Nagayama K. 1993 Cloning, expression and characterization of horse L-ferritin in Escherichia coli. Biochim Biophys Acta 1174, 218-220.

Van Kan PJM, Van der Horst E, Reijerse EJ, Van Bentum PJM, Hagen WR. 1998 Multi-frequency EPR spectroscopy of myoglobin. Spectral effects for high-spin iron (III) ion at high magnetic fields. $J$ Chem Soc Faraday Trans 94, 2975-2978.

Weaver J, Pollack S. 1989 Low-Mr iron isolated from guinea pig reticulocytes as AMP-Fe and ATP-Fe complexes. Biochem J 261, 787-792. 